\title{
Attaining Low Tidal Volume Ventilation During Patient Triggered Ventilation in Sedated Subjects
}

\author{
Moe Koide, Akinori Uchiyama, Tomonori Yamashita, Takeshi Yoshida, and Yuji Fujino
}

\begin{abstract}
BACKGROUND: Low tidal volume $\left(V_{T}\right)$ ventilation has become the preferred approach in patients in the ICU. Sedation reduces $V_{T}$ by attenuating respiratory drive. Even in deep sedation, some patients exhibit high $V_{T}$. We aimed to determine factors associated with low $V_{T}$ ventilation in deeply sedated subjects who exhibited an inspiratory effort by examination of the acid/base balance using the Stewart model. METHODS: The medical records of 630 consecutive subjects admitted to the ICU over $1 \mathrm{y}$ were reviewed retrospectively, and daily data sets of patients with a persistent inspiratory effort, $\mathrm{P}_{\mathrm{aO}_{2}} / \mathrm{F}_{\mathrm{IO}_{2}}<300 \mathrm{~mm} \mathrm{Hg}, \mathrm{PEEP}>5 \mathrm{~cm} \mathrm{H} \mathrm{H}_{2} \mathrm{O}$, and a Richmond Agitation Sedation Scale score of -4 or -5 who received assisted pressure-regulated ventilation were collected. The data sets were stratified into high $V_{T}\left(\geq 8 \mathrm{~mL} / \mathrm{kg}\right.$ predicted body weight [PBW]) and low $V_{T}$ ( $>8 \mathrm{~mL} / \mathrm{kg}$ PBW) groups. RESULTS: Among 235 matched data sets from 100 subjects, 101 and 134 data sets were in the low $V_{T}$ and high $V_{T}$ groups, respectively. Set pressure was not different between the groups. PEEP was lower in the low $V_{T}$ group, and opioids were more frequently used in the high $\mathbf{V}_{T}$ group. Strong ion difference (SID) was higher in the low $\mathbf{V}_{T}$ group. Multivariate analysis revealed that higher SID, lower total nonvolatile weak anion $\left(\mathrm{A}_{\text {тот }}\right)$, and absence of opioid administration were associated with attaining low $V_{T}$ ventilation. Furthermore, $V_{T} / P B W$ and SID demonstrated a weak inverse correlation, whereas $V_{\mathrm{T}} / \mathrm{PBW}$ and $\mathrm{A}_{\text {Tот }}$ exhibited a weak correlation. $V_{T} / P B W$ was lower in the group with higher SID and lower $A_{\text {TOT }}$, indicating a tendency of metabolic alkalosis. CONCLUSIONS: Despite weak effects of high SID and low $\mathbf{A}_{\text {TOT }}$, efficient management of the buffering function might be a feasible strategy to achieve low $\mathbf{V}_{\mathbf{T}}$ ventilation. Key words: acid/base balance; patient triggered ventilation; deep sedation; low tidal volume; Stewart model. [Respir Care 2019;64(8):890-898. ( ) 2019 Daedalus Enterprises]
\end{abstract}

\section{Introduction}

Low tidal volume $\left(\mathrm{V}_{\mathrm{T}}\right)$ ventilation is essential for ensuring lung protection during mechanical ventilation in patients with ARDS. ${ }^{1-4}$ Low $\mathrm{V}_{\mathrm{T}}$ ventilation reportedly reduces postoperative pulmonary complications related to

\footnotetext{
Drs Koide, Uchiyama, Yamashita, Yoshida, and Fujino are affiliated with the Department of Anesthesiology and Intensive Care Medicine, Osaka University Graduate School of Medicine, Suita, Japan.
}

The authors have disclosed no conflicts of interest.

Correspondence: Akinori Uchiyama MD PhD, Department of Anesthesiology and Intensive Care Medicine, Osaka University Graduate School of Medicine, Yamadaoka 2-15, Suita, Osaka Prefecture, 565-0871, Japan. E-mail: auchiyama@hp-icu.med.osaka-u.ac.jp.

DOI: $10.4187 /$ respcare.06197 general anesthesia ${ }^{5-7}$ and improves clinical outcomes of patients without ARDS. ${ }^{8}$ Low $V_{\mathrm{T}}$ ventilation is increasingly preferred in mechanically ventilated patients in the ICU, although its efficacy in routine postoperative patients has not been confirmed. Volume controlled ventilation maintains a low $\mathrm{V}_{\mathrm{T}}$; however, interactions with a patient's inspiratory effort can cause ventilator asynchrony, leading to lung injury. ${ }^{9,10}$ Patient triggered, pressure-regulated ventilation modes, such as pressure controlled ventilation and pressure support ventilation, are alternatives that can resolve ventilator asynchrony ${ }^{11}$; however, maintaining a low $\mathrm{V}_{\mathrm{T}}$ can be difficult in pressure targeted ventilation in subjects with inspiratory effort.

While several studies reported factors associated with low $\mathrm{V}_{\mathrm{T}}$ ventilation, ${ }^{12,13}$ there is limited information on attainment of low $\mathrm{V}_{\mathrm{T}}$ with assisted pressure-regulated ventilation modes in subjects with an inspiratory effort. Low $\mathrm{V}_{\mathrm{T}}$ ventilation can be achieved with appropriate sedation, 
ventilator settings, and the maintenance of arterial blood gases. However, the efficacy of these approaches has not

\section{See the Related Editorial on Page 1021}

been confirmed in subjects maintaining an inspiratory effort. Due to the depressive effects of sedatives on respiration, sedation is expected to reduce $\mathrm{V}_{\mathrm{T}}$ by attenuating respiratory drive. Chen et al ${ }^{12}$ reported that adherence to a low- $\mathrm{V}_{\mathrm{T}}$ strategy was associated with the depth of sedation. Even in deep sedation, some subjects exhibited a high $\mathrm{V}_{\mathrm{T}}$ due to a persistent strong inspiratory effort. Patients often exhibit a strong inspiratory effort because of hypercapnia and abnormal lung mechanics. In addition, other factors such as metabolic acidosis, pain, discomfort, anxiety, and excitation can stimulate the respiratory center. Deep sedation is sometimes necessary to improve the circulatory and respiratory status of patients in the ICU, and it is occasionally needed after cardiac surgery. ${ }^{14}$ This study aimed to determine factors associated with low $\mathrm{V}_{\mathrm{T}}$ ventilation in deeply sedated subjects on patient triggered pressure-regulated ventilation.

The acid/base balance in blood is one of the vital factors that affect respiratory center function. Umoh et al ${ }^{15}$ reported that a low serum $\mathrm{HCO}^{3-}(<22 \mathrm{mEq} / \mathrm{L})$ was negatively correlated with a low $\mathrm{V}_{\mathrm{T}}$. However, serum $\mathrm{HCO}^{3-}$ is also affected by ventilation and $\mathrm{P}_{\mathrm{aCO}}$, which hinders the precise elucidation of metabolic and respiratory factors that affect serum acid/base status. The Stewart model considers the following 3 factors as independent variables to determine the acid/base status ${ }^{16-19}: \mathrm{P}_{\mathrm{aCO}}$; strong ion difference (SID), which is the difference between the sums of all strong cations and all strong anions; and total nonvolatile weak anions $\left(\mathrm{A}_{\mathrm{TOT}}\right)$. Accordingly, $\mathrm{pH}$ and $\mathrm{HCO}^{3-}$ are dependent variables and are altered when one or more of the independent variables change. Thus, the Stewart model facilitates the elucidation of metabolic and respiratory factors separately. Although some studies have utilized the Stewart model to investigate the acid/base status in critically ill subjects, ${ }^{20-24}$ the correlation between the characteristics of mechanical ventilation and the acid/base status according to the Stewart model has not been examined extensively. In this retrospective study, we examined ventilatory characteristics, including $\mathrm{V}_{\mathrm{T}}$, using the Stewart model in a consecutive series of ICU subjects.

\section{Methods}

\section{Study Population}

The medical records of 630 consecutive patients admitted to the medical and surgical ICU of the Osaka University Hospital from January 1, 2014, to December 31, 2014,

\section{QUICK LOOK}

\section{Current knowledge}

Low tidal volume ventilation has become the preferred approach in patients in the ICU. Sedation reduces tidal volume by attenuating respiratory drive. Even in deep sedation, some patients exhibit high tidal volume. Methods of maintaining a low tidal volume in assisted pressure-regulated ventilation remain unclear in deeply sedated patients with a significant inspiratory effort.

\section{What this paper contributes to our knowledge}

Management of the buffering function using the Stewart model is a feasible strategy to achieve a lung protective tidal volume ventilation.

were reviewed retrospectively. $59.2 \%$ of the patients were admitted to the ICU for care after cardiac surgery. Data on arterial blood gases and ventilator and sedation status during the first $14 \mathrm{~d}$ after ICU admission were collected from subjects' records. This study was approved by the Institutional Review Board of Osaka University Hospital (No. 15239).

The mechanical ventilation strategy in the ICU was as follows. The attending ICU physicians determined the ventilator mode and setting adjustments according to the status of each subject. Generally, target $\mathrm{V}_{\mathrm{T}}$ was in the range of 6-8 $\mathrm{mL}$ per $\mathrm{kg}$ predicted body weight (PBW). However, individual target $\mathrm{V}_{\mathrm{T}}$ values were determined by the attending physician according to the status of each subject. The default mechanical ventilation settings were volume controlled synchronized intermittent mandatory ventilation (SIMV) with pressure support ventilation. However, pressure controlled ventilation was used in subjects requiring mechanical ventilation for $>12 \mathrm{~h}$. Pressure targeted ventilation was chosen to maintain better synchrony between the subject's inspiratory effort and the ventilator. Arterial blood gases, which were evaluated regularly every $6 \mathrm{~h}$ by the attending nurse or physician, were assessed more frequently if needed. The mechanical ventilation settings at the time of arterial blood gas measurements were recorded on the subjects' charts.

The following sedation strategy was utilized in the ICU. Richmond Agitation Sedation Scale (RASS) scores were evaluated and recorded hourly during sedation by the attending nurse. The primary goal of sedation in subjects receiving invasive mechanical ventilation is to attain RASS scores of 0 to -2 . In subjects who were deemed to need deep sedation by the attending physician, the target RASS score was set to -4 or -5 . In this study, the primary goal with deep sedation was the stabilization of circulatory status because approximately half of the subjects were in the 
ICU for care after cardiac surgery. The first-line and second-line sedatives were propofol and dexmedetomidine, respectively, and midazolam was added if these 2 drugs were inadequate. For subjects with significantly unstable circulatory status, midazolam was preferred over propofol. If needed, fentanyl or morphine by continuous infusion was used as an analgesic, per the attending physician's evaluation. Bolus opioids were approved and delivered by the attending nurses according to the pain score, which was evaluated every hour based on the critical care pain observation tool. ${ }^{25}$ The target level of pain relief was defined as $<2$. Because most of the subjects in the current study were in postoperative care, the main reason for the narcotics was pain relief of surgical sites.

The strategy for fluid therapy in the ICU was as follows. The basic infusion rate of maintenance fluids was $24 \mathrm{~mL} / \mathrm{kg}$ body weight daily. The attending ICU physician determined the detailed composition and actual infusion rate of the maintenance solutions, according to the subject's status. Balanced acetate Ringer's solution was used as the regular resuscitation fluid. If needed, 5\% human albumin in saline was administered. The regular threshold of blood transfusion was $8 \mathrm{~g} / \mathrm{dL}$ hemoglobin, and the decision to start a blood transfusion was made by the attending ICU physician.

\section{Data Collection}

Data on body weight, height, age, sex, and reason for the ICU admission were collected from the subjects' medical records. Data on $\mathrm{pH}, \mathrm{P}_{\mathrm{aCO}_{2}}, \mathrm{P}_{\mathrm{aO}}, \mathrm{HCO}^{3-}$, lactate, $\mathrm{Na}^{+}$, $\mathrm{K}^{+}$, and $\mathrm{Ca}^{2+}$ were derived from the arterial blood gas measurements using an ABL800 Flex blood gas analyzer (Radiometer, Copenhagen, Denmark). Serum albumin, $\mathrm{Cl}^{-}$, and inorganic phosphate $(\mathrm{P})$ were measured more than once a day at the laboratory of the study hospital; thus, albumin, $\mathrm{Cl}^{-}$, and $P$ values at times that were closest to the times of arterial blood gas measurements were used. The anion gap was calculated according to the following equation ${ }^{16}$ : anion gap $=\mathrm{Na}^{+}-\mathrm{Cl}^{-}-\mathrm{HCO}^{3-}$.

Data sets including mechanical ventilation mode, ventilator setting, ventilator status, blood biochemistry, use of opioids, and body temperature at the time of arterial blood gas measurements were reviewed, and data sets that fulfilled the following inclusion criteria were included in the analyses: $\mathrm{P}_{\mathrm{aO}_{2}} / \mathrm{F}_{\mathrm{IO}_{2}}<300 \mathrm{~mm} \mathrm{Hg}$ with PEEP $\geq 5 \mathrm{~cm} \mathrm{H} \mathrm{H}_{2} \mathrm{O}$; ventilation modes of continuous mandatory ventilation, SIMV, or CPAP with patient triggered pressure-regulated ventilation modes, including pressure controlled ventilation and pressure support ventilation; the presence of spontaneous inspiratory effort confirmed by the difference between the mandatory ventilator rate setting and the actual breathing frequency (if the difference was $\geq 2$, subjects were considered to have a maintained inspiratory effort); and a RASS score $\leq-4$. The exclusion criteria were as follows: presence of a neurological complication affecting respiratory center function; absence of an arterial cannula for continuous pressure monitoring and blood sampling; no usage of invasive mechanical ventilation; age $<18 \mathrm{y}$; support provided by a membrane oxygenation device; and cyanosis due to right-left cardiac shunting. One data set per day was included for each subject; however, if more than one data set fulfilled the study criteria, the data set recorded closest to $12 \mathrm{pm}$ was included in the analyses. Mean $\mathrm{V}_{\mathrm{T}}$ was calculated by dividing minute volume by breathing frequency. Pressure target was based on the pressure support ventilation and pressure controlled ventilation settings. In subjects receiving SIMV, mean pressure target was calculated from the ratio of mandatory ventilation rate and the breathing frequency.

\section{The Stewart Model}

According to the Stewart model, independent variables to determine the acid/base status are $\mathrm{P}_{\mathrm{aCO}_{2}}$, SID, and $\mathrm{A}_{\text {TOT }}$. In our study, the following formulae were used to determine the acid/base status 26 :

- $\mathrm{SID}=\mathrm{Na}^{+}+\mathrm{K}^{+}+\mathrm{Ca}^{2+}+\mathrm{Mg}^{2+}-\mathrm{Cl}^{-}-$lactate

- $\mathrm{A}_{\mathrm{TOT}}=\operatorname{albumin}(\mathrm{g} / \mathrm{L}) \times(0.123 \times \mathrm{pH}-0.631)+\mathrm{P}$ $(\mathrm{mmol} / \mathrm{L}) \times(0.309 \times \mathrm{pH}-0.469)$

- strong ion gap $=\mathrm{SID}-\mathrm{A}_{\mathrm{TOT}}-\mathrm{HCO}^{3-}$

Although $\mathrm{Mg}^{2+}$ measurements were not included in the routine chemistry profile at the study institution, changes in $\mathrm{Mg}^{2+}$ are typically very small and can be neglected, so a constant $\mathrm{Mg}^{2+}$ value can be assumed in these formulas. In this study, a constant $\mathrm{Mg}^{2+}$ value of $1.7 \mathrm{mEq} / \mathrm{L}$ was used, as described previously. ${ }^{20}$

All data sets were described based on the $\mathrm{V}_{\mathrm{T}} / \mathrm{PBW}$ ratio into low $\mathrm{V}_{\mathrm{T}}(<8 \mathrm{~mL} / \mathrm{kg})$ and high $\mathrm{V}_{\mathrm{T}}(\geq 8 \mathrm{~mL} / \mathrm{kg})$ groups to determine factors associated with low $\mathrm{V}_{\mathrm{T}} / \mathrm{PBW}$. In addition, all collected data were categorized by 2 independent variables, SID and $\mathrm{A}_{\mathrm{TOT}}$, according to the Stewart model to evaluate non-respiratory (metabolic) acid/base status. Of note, lower SID and higher $\mathrm{A}_{\text {TOT }}$ levels are causative factors of metabolic acidosis. Accordingly, the data sets were further divided into 4 groups to examine the achievement of a low $\mathrm{V}_{\mathrm{T}}$ /PBW under the Stewart model: high SID with low $\mathrm{A}_{\mathrm{TOT}}$, high SID with high $\mathrm{A}_{\text {TOT }}$, low SID with low $\mathrm{A}_{\text {TOT }}$, and low SID with high $\mathrm{A}_{\text {TOT }}$. Median SID and $\mathrm{A}_{\text {Tот }}$ values were used as cutoff values to categorize the high and low groups for both parameters.

\section{Statistical Analysis}

Continuous variables were compared using the MannWhitney $U$ test or the Kruskal-Wallis test. Categorical 
variables were expressed as numbers with percentages, and values were compared using the chi-square test. In addition, post hoc analysis was performed as needed per the Steel-Dwass method. Univariate analyses of data set characteristics were conducted to determine factors associated with the risk of not adhering to the low $\mathrm{V}_{\mathrm{T}}$ ventilation policy. Predictive factors with a $P<.2$ in univariate analyses were included in a multivariate logistic regression model. In addition, linear regression analysis was performed to elucidate the correlation of SID, $\mathrm{A}_{\mathrm{TOT}}$, and $\mathrm{V}_{\mathrm{T}} / \mathrm{PBW}$ with the low $\mathrm{V}_{\mathrm{T}}$ ventilation policy. For all analyses, $P<.05$ was considered as statistically significant. All data were analyzed with the JMP statistical software version 12.2 (SAS Institute, Cary, North Carolina).

\section{Results}

During the study period, 630 patients were admitted to the ICU; of these, 100 subjects who fulfilled the inclusion criteria provided 235 individual data sets of clinical and ventilator parameters (Fig. 1). Table 1 summarizes the characteristics of the matched data sets included in this study. Of these $235 \mathrm{~V}_{\mathrm{T}} / \mathrm{PBW}$ data sets, 101 and 134 data sets were in the low and high $\mathrm{V}_{\mathrm{T}}$ groups, respectively. In addition, the $\mathrm{V}_{\mathrm{T}}$ /actual body weight and PEEP values were lower in the low $\mathrm{V}_{\mathrm{T}}$ group than in the high $\mathrm{V}_{\mathrm{T}}$ group. Furthermore, the breathing frequency, $\mathrm{P}_{\mathrm{aCO}_{2}}, \mathrm{HCO}^{3-}$, and SID were higher in the low $\mathrm{V}_{\mathrm{T}}$ group than in the high $\mathrm{V}_{\mathrm{T}}$ group, whereas, opioids were used more frequently in the high $\mathrm{V}_{\mathrm{T}}$ group than in the low $\mathrm{V}_{\mathrm{T}}$ group.

The subjects providing these 235 data sets included 34 subjects in the low $\mathrm{V}_{\mathrm{T}}$ group, 49 subjects in the high $\mathrm{V}_{\mathrm{T}}$ group, and 17 subjects who overlapped both the low and high $\mathrm{V}_{\mathrm{T}}$ groups. The actual body weights of subjects in the high $\mathrm{V}_{\mathrm{T}}$ group were higher than those of subjects in the low $\mathrm{V}_{\mathrm{T}}$ group; however, the differences in other characteristics among the 3 groups were not significant (Table 2).

Table 3 shows the results of the univariate logistic analysis. PEEP, SID, and absence of opioid administration were associated with the attainment of a low $\mathrm{V}_{\mathrm{T}}$. The multivariate logistic analysis included 7 parameters based on the results of the univariate logistic analysis. The number of mechanical ventilation days represented the disease stage, SOFA score represented the severity of the clinical condition, PEEP represented the mechanical ventilation settings, $\mathrm{P}_{\mathrm{aO}_{2}} / \mathrm{F}_{\mathrm{IO}_{2}}$ indicated lung function, SID represented the acid/base balance of a strong ion, $\mathrm{A}_{\text {TOT }}$ represented the $\mathrm{acid} / \mathrm{base}$ balance of a weak ion, and the use of opioids represented the drug treatment. Table 4 shows the results of the multivariate logistic analysis. SID, $\mathrm{A}_{\mathrm{TOT}}$, and the use of opioids were associated with $\mathrm{V}_{\mathrm{T}} / \mathrm{PBW}$. The median (interquartile range) $\mathrm{V}_{\mathrm{T}} / \mathrm{PBW}$ in subjects who were administered intravenous opioids was significantly higher

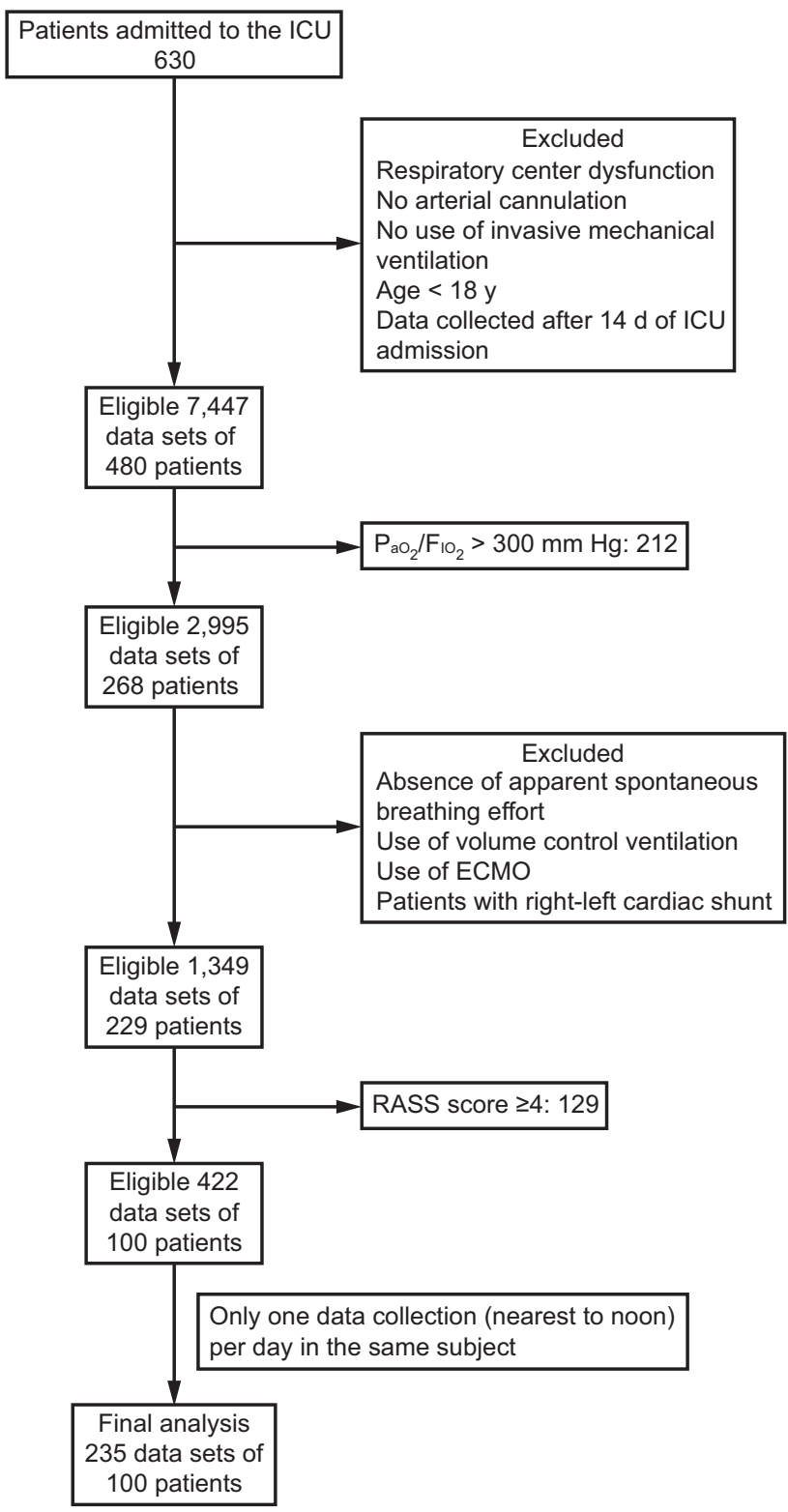

Fig. 1. Flow chart. ECMO = extracorporeal membrane oxygenation.

than the median $\mathrm{V}_{\mathrm{T}} / \mathrm{PBW}$ in subjects who did not receive intravenous opioids (8.36 [7.41-9.50] vs 7.67 [6.57$9.13] \mathrm{mL} / \mathrm{kg}$ PBW, $P=.01$ ). Regression analysis revealed that $\mathrm{V}_{\mathrm{T}} / \mathrm{PBW}$ and SID exhibited a weak inverse correlation and that $\mathrm{V}_{\mathrm{T}} / \mathrm{PBW}$ and $\mathrm{A}_{\text {TOт }}$ had a weak correlation (Fig. 2).

Figure 3 shows the distribution of all collected data on the $\mathrm{A}_{\text {TOT }}$-SID plane. In this study, the distribution of the data sets was as follows: high SID with low $\mathrm{A}_{\mathrm{TOT}}$ (no. $=46$ ), high SID with high $\mathrm{A}_{\text {Tот }}$ (no. = 71), low SID with low $\mathrm{A}_{\text {TOT }}$ (no. $=72$ ), and low SID with high $\mathrm{A}_{\text {TOT }}$ (no. $=46$ ). The cutoff values for SID and $A_{\text {TOT }}$ were median values derived from the data sets of the entire study $(41.8 \mathrm{mEq} / \mathrm{L}$ 
Table 1. Characteristics of Data Sets

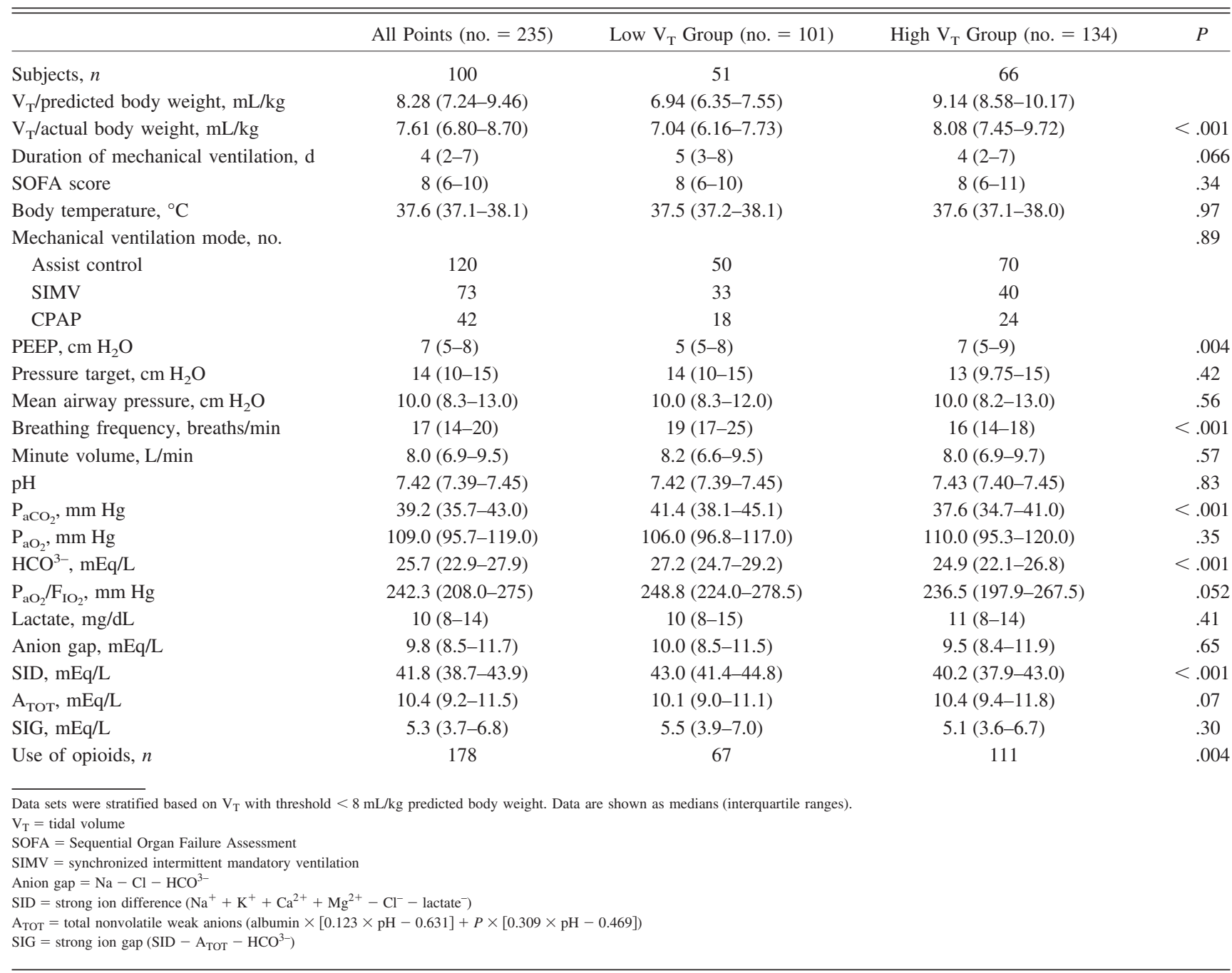

Table 2. Characteristics of Subjects Whose Data Sets Were Classified as High $\mathrm{V}_{\mathrm{T}}$, Low $\mathrm{V}_{\mathrm{T}}$, and Overlapping $\mathrm{V}_{\mathrm{T}}$ Groups

\begin{tabular}{|c|c|c|c|c|}
\hline & Low $\mathrm{V}_{\mathrm{T}}$ & High $\mathrm{V}_{\mathrm{T}}$ & Overlapping $\mathrm{V}_{\mathrm{T}}$ & $P$ \\
\hline Subjects, $n$ & 34 & 49 & 17 & \\
\hline Age, y & $62(48-74)$ & $66(60-75)$ & $66(60-71)$ & .27 \\
\hline Male, $n$ & 26 & 36 & 12 & .90 \\
\hline Body weight, $\mathrm{kg}$ & $56.3(49.3-64.0)$ & $62.3(57.3-72.0)^{*}$ & $61.0(53.6-69.5)$ & .034 \\
\hline Body length, cm & $166.5(154.4-170.6)$ & $161.5(156.1-165.2)$ & $162.5(153.7-169.9)$ & .36 \\
\hline Reason for admission to ICU, $n$ & & & & .45 \\
\hline Post-cardiac surgery & 24 & 42 & 14 & \\
\hline Post-thoracic surgery & 1 & 2 & 1 & \\
\hline Post-transplantation & 3 & 3 & 0 & \\
\hline Cardiac failure & 0 & 1 & 1 & \\
\hline Renal failure & 2 & 0 & 0 & \\
\hline Respiratory failure & 3 & 1 & 1 & \\
\hline Sepsis & 1 & 0 & 0 & \\
\hline \multicolumn{5}{|c|}{$\begin{array}{l}\text { The threshold was } \mathrm{V}_{\mathrm{T}}<8 \mathrm{~mL} / \mathrm{kg} \text { predicted body weight. Data are shown as medians (interquartile ranges). } \\
\begin{array}{l}* P<.05 \text { compared to the low } \mathrm{V}_{\mathrm{T}} \text { with post-hoc Steel-Dwass test. } \\
\mathrm{V}_{\mathrm{T}}=\text { tidal volume }\end{array}\end{array}$} \\
\hline
\end{tabular}


Table 3. Univariate Analysis of Variables Associated With Attainment of Low $\mathrm{V}_{\mathrm{T}}$ Ventilation

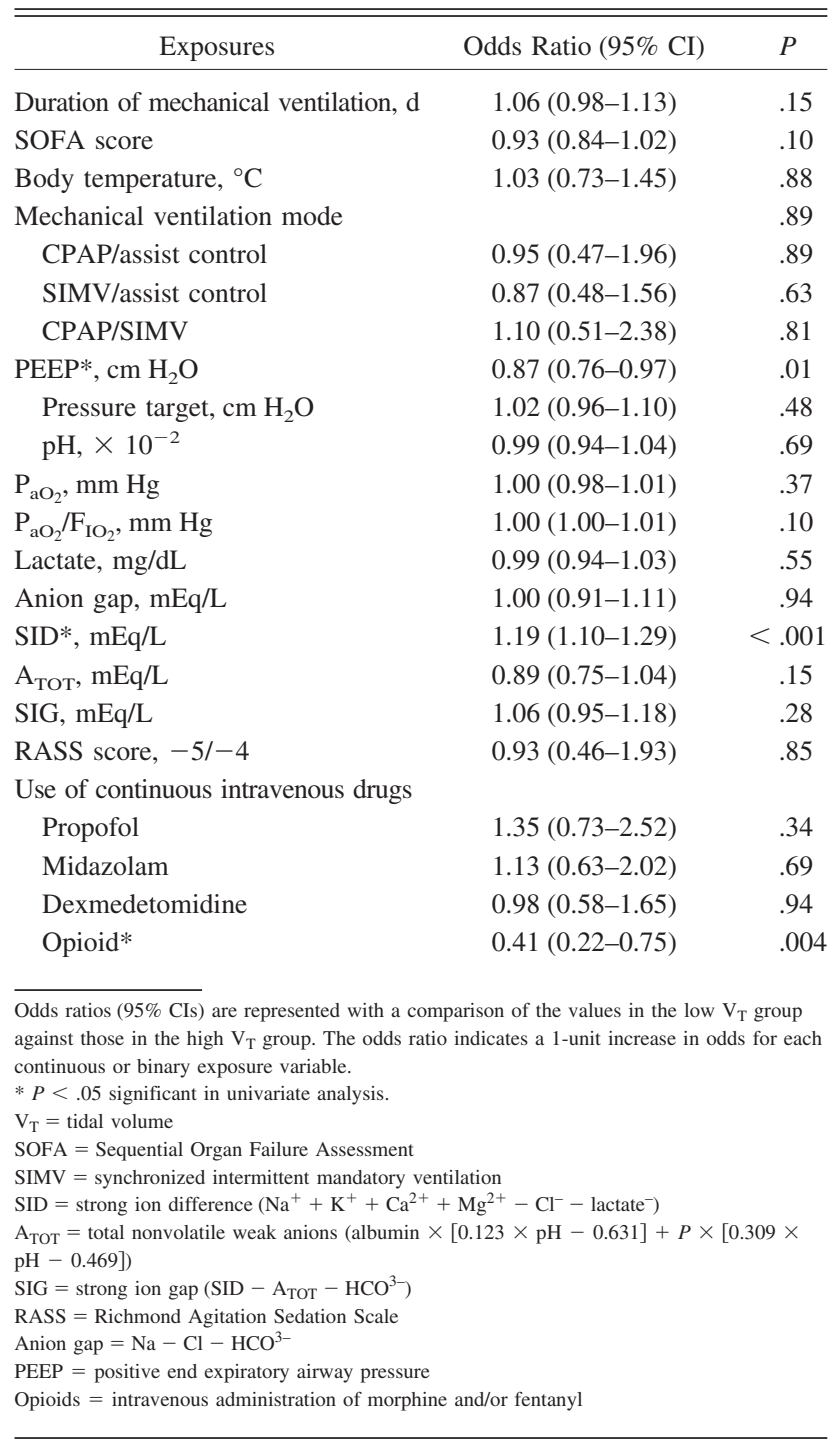

for SID and $10.4 \mathrm{mEq} / \mathrm{L}$ for $\mathrm{A}_{\text {TOT }}$ ). Importantly, the $\mathrm{V}_{\mathrm{T}} / \mathrm{PBW}$ in the group with high SID and low $\mathrm{A}_{\text {TOT }}$ was significantly lower than those in the other 3 groups (Fig. 4).

\section{Discussion}

In this retrospective study, SID, $\mathrm{A}_{\mathrm{TOT}}$, and the use of opioids were associated with the attainment of low $\mathrm{V}_{\mathrm{T}}$ in deeply sedated subjects with preserved inspiratory effort. $\mathrm{V}_{\mathrm{T}} / \mathrm{PBW}$ was significantly lower in in the presence of high SID with low $\mathrm{A}_{\text {TOT }}$, indicating a tendency of metabolic alkalosis.

The inspiratory drive of the respiratory center is affected by the $\mathrm{pH}$ of the cerebrospinal fluid in the medulla
Table 4. Multivariate Analysis of Variables Associated With the Attainment of Low $V_{T}$ Ventilation

\begin{tabular}{|c|c|c|}
\hline Exposures & Odds Ratio (95\% CI) & $P$ \\
\hline $\begin{array}{l}\text { Duration of mechanical } \\
\text { ventilation, } d\end{array}$ & $1.00(0.92-1.10)$ & .94 \\
\hline SOFA score & $1.01(0.89-1.14)$ & .88 \\
\hline PEEP, $\mathrm{cm} \mathrm{H}_{2} \mathrm{O}$ & $0.87(0.74-1.01)$ & .066 \\
\hline $\mathrm{P}_{\mathrm{aO}_{2}} / \mathrm{F}_{\mathrm{IO}_{2}}, \mathrm{~mm} \mathrm{Hg}$ & $1.00(0.99-1.01)$ & .79 \\
\hline $\mathrm{SID}, \mathrm{mEq} / \mathrm{L}^{*}$ & $1.22(1.12-1.33)$ & $<.001$ \\
\hline $\mathrm{A}_{\mathrm{TOT}}, \mathrm{mEq} / \mathrm{L}^{*}$ & $0.79(0.65-0.96)$ & .02 \\
\hline $\begin{array}{l}\text { Use of continuous } \\
\text { intravenous opioids* }\end{array}$ & $0.39(0.19-0.78)$ & .008 \\
\hline \multicolumn{3}{|c|}{$\begin{array}{l}\text { Odds ratio (95\% CIs) are represented with a comparison of the values in the low } \mathrm{V}_{\mathrm{T}} \text { group } \\
\text { against those in the high } \mathrm{V}_{\mathrm{T}} \text { group. The odds ratio indicates a 1-unit increase in odds for each } \\
\text { continuous or binary exposure variable. } \\
* P<.05 \text { significant in multivariate analysis. } \\
\mathrm{V}_{\mathrm{T}}=\text { tidal volume } \\
\text { SOFA = Sequential Organ Failure Assessment } \\
\text { SID }=\text { strong ion difference }\left(\mathrm{Na}^{+}+\mathrm{K}^{+}+\mathrm{Ca}^{2+}+\mathrm{Mg}^{2+}-\mathrm{Cl}^{-}-\text {lactate }\right. \\
\mathrm{A}_{\mathrm{TOT}}=\text { total nonvolatile weak anions (albumin } \times[0.123 \times \mathrm{pH}-0.631]+P \times[0.309 \times \\
\mathrm{pH}-0.469])\end{array}$} \\
\hline
\end{tabular}

as well as the serum $\mathrm{pH}$ level detected by the peripheral chemoreceptor. ${ }^{27}$ The inspiratory drive can be controlled by the management of the buffering function of the serum. Our multivariate logistic analysis suggested that SID and $\mathrm{A}_{\text {Tот }}$ were associated with adherence to low $\mathrm{V}_{\mathrm{T}}$ ventilation. In the context of the acid/base balance, higher SID and lower $\mathrm{A}_{\text {Tот }}$ might reduce $\mathrm{V}_{\mathrm{T}} / \mathrm{PBW}$ in deeply sedated patients with persistent inspiratory effort. The current findings suggested that $\mathrm{V}_{\mathrm{T}} / \mathrm{PBW}$ correlated with SID and $\mathrm{A}_{\text {TOT }}$. Despite the weak effects of a higher SID and a lower $\mathrm{A}_{\text {TOT }}$, efficient management of the buffering function of the serum might be a feasible strategy to achieve low $\mathrm{V}_{\mathrm{T}}$ ventilation. For example, SID can be increased by the administration of sodium bicarbonate, whereas a low serum albumin level can attain a low $\mathrm{A}_{\text {TOT }}$.

It is difficult to determine the normal ranges of SID and $\mathrm{A}_{\text {тот }}$ because their definitions differ among studies. In our study, the cutoff values of SID and $\mathrm{A}_{\text {TOT }}$ were 41.8 and $10.4 \mathrm{mEq} / \mathrm{L}$, respectively. In a study by Dubin et al, ${ }^{21}$ the mean SID and $\mathrm{A}_{\text {Тот }}$ of normal volunteers were 40.8 and $15.0 \mathrm{mEq} / \mathrm{L}$, respectively, whereas those of the ICU subjects $(n=935)$ were 39.7 and $11.0 \mathrm{mEq} / \mathrm{L}$, respectively. In addition, Boniatti et $\mathrm{a}^{22}$ reported that the mean SID and $\mathrm{A}_{\text {тот }}$ of survivors were 35.5 and $10.5 \mathrm{mEq} / \mathrm{L}$, respectively, and those of non-survivors were 32.9 and $8.6 \mathrm{mEq} / \mathrm{L}$, respectively, among a cohort of 175 ICU subjects; they also defined the normal ranges of SID as $40-44 \mathrm{mEq} / \mathrm{L}$. Kaplan and Kellum ${ }^{23}$ demonstrated that the mean SID of survivors and non-survivors were 37.5 and $31.4 \mathrm{mEq} / \mathrm{L}$, respectively, among a cohort of trauma subjects requiring vascular repair. The cutoff values in our study, therefore, were within previously reported normal ranges for ICU patients. In addition, SID demonstrated a weak positive 

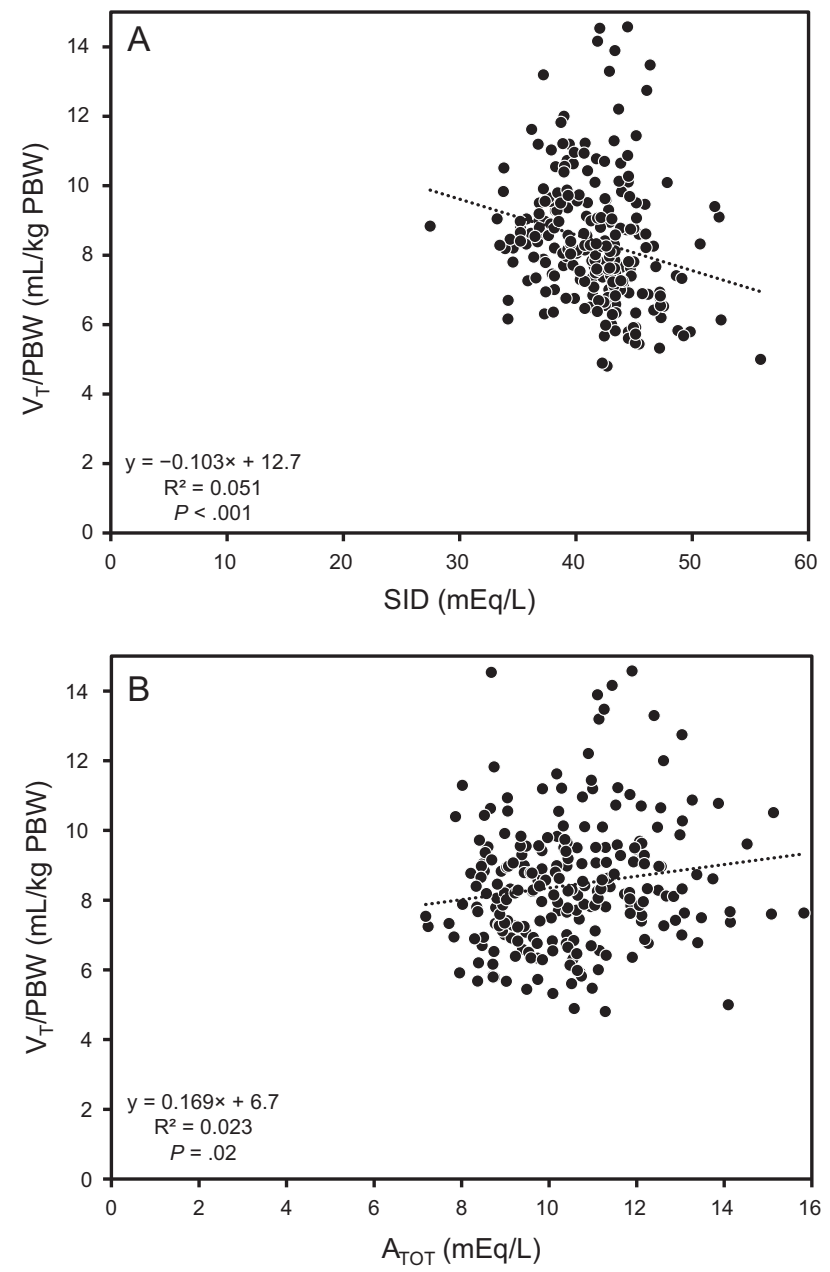

Fig. 2. Regression analysis between strong ion difference (SID) (A), and total nonvolatile weak anion $\left(\mathrm{A}_{\mathrm{TOT}}\right)(\mathrm{B})$ and ratio of tidal volume $\left(V_{T}\right)$ to predicted body weight $\left(V_{T} / P B W\right)$. $V_{T} / P B W$ exhibits a weak inverse correlation with SID. $\mathrm{V}_{\mathrm{T}} / \mathrm{PBW}$ and $\mathrm{A}_{\mathrm{TOT}}$ exhibit a weak correlation.

correlation with $\mathrm{A}_{\mathrm{TOT}}$, which was described previously. ${ }^{24}$ Metabolic alkalosis due to a low $\mathrm{A}_{\text {Tот }}$, such as that induced by hypoalbuminemia, might have been compensated by a decrease in SID.

The normal target $\mathrm{V}_{\mathrm{T}}$ range is $6-8 \mathrm{~mL} / \mathrm{kg} \mathrm{PBW}$ in the ICU. Targeted $\mathrm{V}_{\mathrm{T}}$ for lung protection differs among published studies, with the strictest threshold reported as $<6 \mathrm{~mL} / \mathrm{kg}$ PBW in subjects with ARDS. ${ }^{28}$ Fuiter et $\mathrm{al}^{5}$ reported that the use of $6-8 \mathrm{~mL} / \mathrm{kg}$ PBW as target $\mathrm{V}_{\mathrm{T}}$ during general anesthesia for major abdominal surgery was associated with improved clinical outcomes and reduced health care utilization. In a meta-analysis, Neto et $\mathrm{al}^{8}$ reported that a mean $\mathrm{V}_{\mathrm{T}}$ of $6.45 \mathrm{~mL} / \mathrm{kg}$ ideal body weight was associated with improved outcomes in subjects without ARDS. In our study, we selected $<8 \mathrm{~mL} / \mathrm{kg}$ PBW as the low $\mathrm{V}_{\mathrm{T}}$ ventilation threshold, which was similar to that selected by Cooke et al. ${ }^{29}$ Although $<8 \mathrm{~mL} / \mathrm{kg}$ PBW is a lenient definition of low $\mathrm{V}_{\mathrm{T}}$ ventilation, it is within the

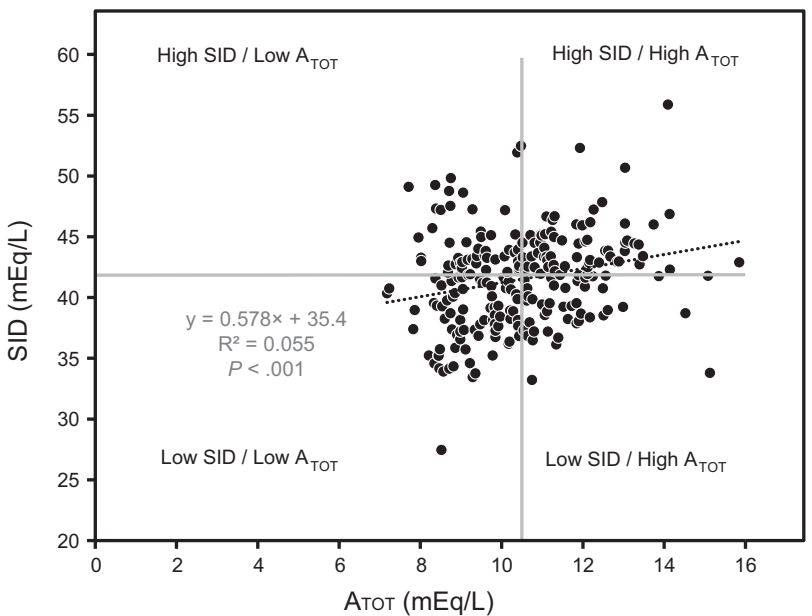

Fig. 3. Distribution of all collected data on the total nonvolatile weak anion $\left(\mathrm{A}_{\text {TOT }}\right.$ ) and strong ion difference (SID) plane. SID and $\mathrm{A}_{\text {TOт }}$ exhibit a weak correlation. The data are divided into 4 groups: high SID with low $A_{\text {TOT, }}$, high SID with high $A_{\text {TOT, }}$, low SID with low $A_{\text {TOT }}$, and low SID with high $A_{\text {TOT. }}$. The high and low cutoff values for SID and $A_{\text {Tот }}$ are based on median values (41.8 mEq/L SID; $10.4 \mathrm{mEq} / \mathrm{L} \mathrm{A}_{\text {TOT }}$ ).

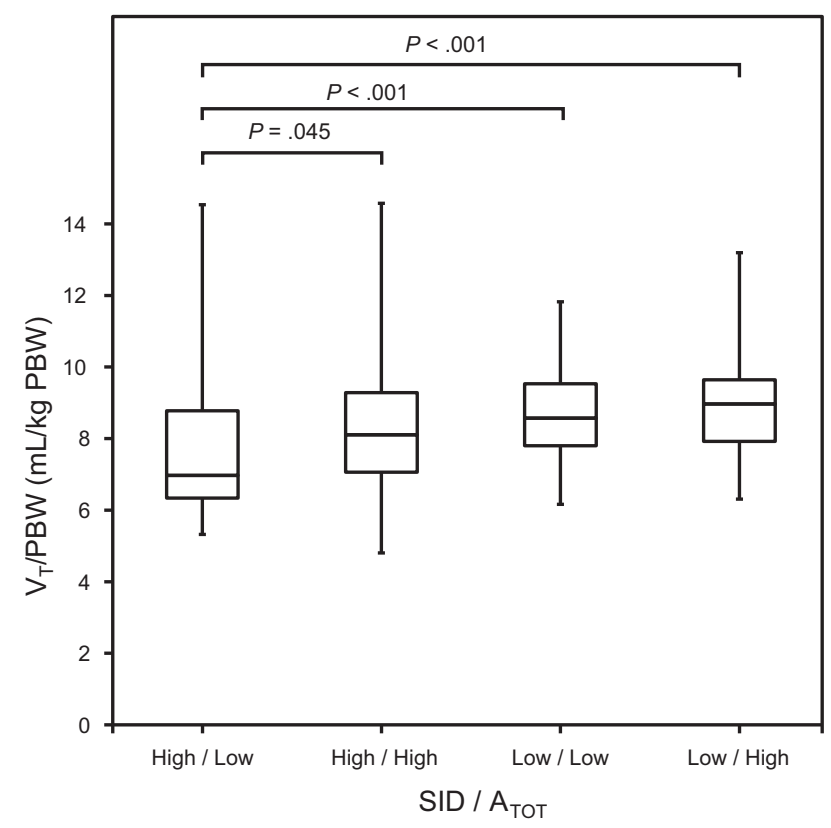

Fig. 4. Tidal volume $\left(\mathrm{V}_{\mathrm{T}}\right)$ /predicted body weight $\left(\mathrm{V}_{\mathrm{T}} / \mathrm{PBW}\right)$ in the 4 groups divided according to strong ion difference (SID) and total nonvolatile weak anion $\left(\mathrm{A}_{\text {TOT }}\right)$ values. The data are expressed as a medians with interquartile ranges. $\mathrm{V}_{\mathrm{T}} / \mathrm{PBW}$ in the group with high SID and low $A_{\text {TOT }}$ is significantly lower than those in the other 3 groups.

upper $95 \% \mathrm{CI}$ boundary of the low $\mathrm{V}_{\mathrm{T}}$ ventilation arm of the ARDSNet ARMA study. ${ }^{2}$

Reducing $\mathrm{V}_{\mathrm{T}}$ in critically ill patients on mechanical ventilation is not easy. Bellani et al ${ }^{30}$ reported a $V_{T}$ of $>8 \mathrm{~mL} / \mathrm{kg}$ PBW in more than one third of all subjects with ARDS. In 
a systematic review of 93 studies in subjects with ARDS, conducted after the ARMA study, Jaswal et al ${ }^{28}$ concluded that achieving a $\mathrm{V}_{\mathrm{T}}$ of $\leq 6 \mathrm{~mL} / \mathrm{kg}$ PBW might not be easy because the mean $\mathrm{V}_{\mathrm{T}}$ was $>6 \mathrm{~mL} / \mathrm{kg} \mathrm{PBW}$. Neto et al ${ }^{8}$ reported that low $\mathrm{V}_{\mathrm{T}}$ ventilation was achieved in $50.2 \%$ of subjects without ARDS in their meta-analysis. In our study, $43.0 \%$ of the matched $\mathrm{V}_{\mathrm{T}} / \mathrm{PBW}$ data sets were classified as low $\mathrm{V}_{\mathrm{T}}$. Despite the lenient low $\mathrm{V}_{\mathrm{T}}$ criterion in the current study, the rate of low $V_{T}$ ventilation attainment was lower than that reported in previous studies.

The most popular approach to attain low $\mathrm{V}_{\mathrm{T}}$ ventilation is a reduction in the pressure target. Neto et $\mathrm{al}^{8}$ reported that the mean pressure target was lower in subjects with low $\mathrm{V}_{\mathrm{T}}$ $\left(10.2 \mathrm{~cm} \mathrm{H}_{2} \mathrm{O}\right)$ than those with high $\mathrm{V}_{\mathrm{T}}\left(17.9 \mathrm{~cm} \mathrm{H}_{2} \mathrm{O}\right)$. In our study, the mean pressure target of the low and high $\mathrm{V}_{\mathrm{T}}$ groups did not differ and were comparable to that of subjects with low $\mathrm{V}_{\mathrm{T}}$ levels in the study by Neto et al. ${ }^{8}$ One difference between our study and previous reports is the presence of a spontaneous breathing effort, which was not explicitly reported in a majority of previous studies. In our study, $\mathrm{V}_{\mathrm{T}}$ would have decreased if the pressure target had been set lower by the attending physicians. However, an increasing inspiratory drive might preserve $\mathrm{V}_{\mathrm{T}}$. Restricting the pressure target levels might have a limited effect on reducing the $\mathrm{V}_{\mathrm{T}}$ in patients with persisting inspiratory efforts. Chen et $\mathrm{al}^{12}$ reported that the adherence to a low $\mathrm{V}_{\mathrm{T}}$ strategy was related to the use of muscle relaxants that suppressed inspiratory muscle activity.

\section{Limitations}

The subjects in our study were selected based on the $\mathrm{P}_{\mathrm{aO}_{2}} / \mathrm{F}_{\mathrm{IO}_{2}}$ ratio according to the Berlin ARDS definition for lung oxygenation. We used the Berlin ARDS definition because subjects with deteriorated lung oxygenation are considered to be affected more by low $\mathrm{V}_{\mathrm{T}}$ ventilation. Low $\mathrm{V}_{\mathrm{T}}$ ventilation might be associated with improved outcomes in ICU patients receiving ventilatory support for other reasons. Further investigation is thus needed to examine the attainment of low $\mathrm{V}_{\mathrm{T}}$ ventilation in subjects without impaired lung oxygenation.

Most of the subjects in our study were admitted to the ICU after cardiac surgery and put under deep sedation for circulatory stabilization. However, the cause could not be determined in all subjects. The study subjects differed from other critically ill populations, especially those intubated for primary respiratory failure. Therefore, it remains unclear whether the results would be different in subjects with respiratory issues as the primary cause of deep sedation.

Our results suggest that the absence of opioid administration was associated with the attainment of low $\mathrm{V}_{\mathrm{T}}$ ventilation. This finding does not conflict with known respi- ratory center depression by opioids, which is mainly evident as a decrease in the breathing frequency. The administration of opioids can also affect the depth of sedation. The nurses in the ICU evaluated the subjects using the RASS scale and pain score every hour, and opioids and sedatives were administered accordingly. To date, no methods can precisely evaluate the depth of sedation and analgesia in ICU patients. In this study, we used RASS scores to evaluate the depth of sedation, which is challenging in patients in the ICU, and the actual depth of sedation might not have been comparable between the groups. It is very difficult to evaluate pain relief in deeply sedated patients, and the difficulty of separating the effects of sedatives from those of opioids is a limitation of this study. Further study is needed to examine the sole effect of opioids on $\mathrm{V}_{\mathrm{T}}$ in ICU subjects on mechanical ventilation.

The presence of an inspiratory effort was confirmed by a difference between the total and set breathing frequency and the ventilation frequency settings, as described previously. ${ }^{29,30}$ However, it is challenging to assess the level of inspiratory effort precisely. Hence, the presence of an inspiratory effort in entire synchrony with ventilator support remains a possibility. In this study, there is a possibility that not all data sets of the existing inspiratory efforts were collected. Because monitoring esophageal pressure or diaphragmatic electromyography is necessary for precise detection of the inspiratory effort, further studies are warranted to assess the effects of inspiratory effort on low $\mathrm{V}_{\mathrm{T}}$ ventilation.

Rapid changes in their status, as well as baseline characteristics of the subjects, affected $\mathrm{V}_{\mathrm{T}}$. Therefore, although subject and ventilation data were collected daily in this study, the volume of data collected differed among the subjects. A previous study demonstrated that adherence to a low $\mathrm{V}_{\mathrm{T}}$ strategy was associated with the severity of lung injury, ${ }^{12}$ thus the results regarding adherence to low $\mathrm{V}_{\mathrm{T}}$ ventilation might have been significantly affected by the subject characteristics in this study. Therefore, due to the inherent limitations of a retrospective single-center study, a prospective study is warranted to investigate the effects of baseline subject characteristics and instantaneous changes in subject status on the attainment of low $\mathrm{V}_{\mathrm{T}}$ ventilation in critically ill subjects.

\section{Conclusion}

Despite the weak effects of SID and $\mathrm{A}_{\mathrm{TOT}}$, efficient management of the buffering function of the serum might be a feasible strategy to achieve low $\mathrm{V}_{\mathrm{T}}$ ventilation. Absence of opioid administration was also associated with the attainment of low $V_{T}$ ventilation in subjects with persisting inspiratory effort. 


\section{Low $\mathrm{V}_{\mathrm{T}}$ Ventilation in Sedated Subjects}

\section{REFERENCES}

1. Needham DM, Yang T, Dinglas VD, Mendez-Tellez PA, Shanholtz C, Sevransky JE, et al. Timing of low tidal volume ventilation and intensive care unit mortality in acute respiratory distress syndrome: a prospective cohort study. Am J Respir Crit Care Med 2015;191(2): 177-185.

2. Acute Respiratory Distress Syndrome Network, Brower RG, Matthay MA, Morris A, Schoenfeld D, Thompson BT, Wheeler A. Ventilation with lower tidal volumes as compared with traditional tidal volumes for acute lung injury and the acute respiratory distress syndrome. N Engl J Med 2000;342(18):1301-1308.

3. Petrucci N, De Feo C. Lung protective ventilation strategy for the acute respiratory distress syndrome. Cochrane Database Syst Rev 2013;2:CD003844.

4. Ochiai R. Mechanical ventilation of acute respiratory distress syndrome. J Intensive Care 2015;3(1):25-33.

5. Futier E, Constantin JM, Paugam-Burtz C, Pascal J, Eurin M, Neuschwander A, et al. A trial of intraoperative low-tidal-volume ventilation in abdominal surgery. N Engl J Med 2013;369(5):428-437.

6. Guay J, Ochroch EA. Intraoperative use of low volume ventilation to decrease postoperative mortality, mechanical ventilation, lengths of stay and lung injury in patients without acute lung injury. Cochrane Database Syst Rev 2015;12:CD011151.

7. Severgnini P, Selmo G, Lanza C, Chiesa A, Frigerio A, Bacuzzi A, et al. Protective mechanical ventilation during general anesthesia for open abdominal surgery improves postoperative pulmonary function. Anesthesiology 2013;118(6):1307-1321.

8. Neto AS, Cardoso SO, Manetta JA, Pereira VG, Espósito DC, Pasqualucci Mde $\mathrm{O}$, et al. Association between use of lung-protective ventilation with lower tidal volumes and clinical outcomes among patients without acute respiratory distress syndrome: a meta-analysis. JAMA 2012;308(16):1651-1659.

9. Rittayamai N, Katsios CM, Beloncle F, Friedrich JO, Mancebo J, Brochard L. Pressure-controlled vs volume-controlled ventilation in acute respiratory failure: a physiology-based narrative and systematic review. Chest 2015;148(2):340-355

10. MacIntyre NR, McConnell R, Cheng KC, Sane A. Patient-ventilator flow dyssynchrony: flow-limited versus pressure-limited breaths. Crit Care Med 1997;25(10):1671-1677.

11. Yang LY, Huang YC, Macintyre NR. Patient-ventilator synchrony during pressure-targeted versus flow-targeted small tidal volume assisted ventilation. J Crit Care 2007;22(3):252-257.

12. Chen YF, Lim CK, Ruan SY, Jerng JS, Lin JW, Kuo PH, et al. Factors associated with adherence to low-tidal volume strategy for acute lung injury and acute respiratory distress syndrome and their impacts on outcomes: an observational study and propensity analysis. Minerva Anestesiol 2014;80(11):1158-1168.

13. Weiss CH, Baker DW, Weiner S, Bechel M, Ragland M, Rademaker A, et al. Low tidal volume ventilation use in acute respiratory distress syndrome. Crit Care Med 2016;44(8):1515-1522.
14. Celis-Rodríguez E, Birchenall C, de la Cal MÁ, Castorena Arellano G, Hernández A, Ceraso D, et al. Clinical practice guidelines for evidence-based management of sedoanalgesia in critically ill adult patients. Med Intensiva 2013;37(8):519-574.

15. Umoh NJ, Fan E, Mendez-Tellez PA, Sevransky JE, Dennison CR, Shanholtz C, et al. Patient and intensive care unit organizational factors associated with low tidal volume ventilation in acute lung injury. Crit Care Med 2008;36(5):1463-1468.

16. Seifter JL. Integration of acid-base and electrolyte disorders. N Engl J Med 2014;371(6):1821-1831.

17. Masevicius FD, Dubin A. Has the Stewart approach improved our ability to diagnose acid-base disorders in critically ill patients? World J Crit Care Med 2015;4(1):62-70.

18. Story DA. Stewart acid-base: a simplified bedside approach. Anesth Analg 2016;123(2):511-515.

19. Fencl V, Leith DE. Stewart's quantitative acid-base chemistry: applications in biology and medicine. Respir Physiol 1993;91(1):1-16.

20. Fencl V, Jabor A, Kazda A, Figge J. Diagnosis of metabolic acidbase disturbances in critically ill patients. Am J Respir Crit Care Med 2000;162(6):2246-2251.

21. Dubin A, Menises MM, Masevicius FD, Moseinco MC, Kutscherauer DO, Ventrice E, et al. Comparison of three different methods of evaluation of metabolic acid-base disorders. Crit Care Med 2007; 35(5):1264-1270.

22. Boniatti MM, Cardoso PR, Castilho RK, Vieira SR. Acid-base disorders evaluation in critically ill patients: we can improve our diagnostic ability. Intensive Care Med 2009;35(8):1377-1382.

23. Kaplan LJ, Kellum JA. Initial pH, base deficit, lactate, anion gap, strong ion difference, and strong ion gap predict outcome from major vascular injury. Crit Care Med 2004;32(5):1120-1124.

24. Wilkes P. Hypoproteinemia, strong-ion difference, and acid-base status in critically ill patients. J Appl Physiol 1998;84(5):1740-1748.

25. Gélinas C, Fillion L, Puntillo KA, Viens C, Fortier M. Validation of the critical-care pain observation tool in adult patients. Am J Crit Care 2006;15(4):420-427.

26. Stewart PA. Modern quantitative acid-base chemistry. Can J Physiol Pharmacol 1983;61(12):1444-1461.

27. Lumb AB, Pearl RG. Nunn's applied respiratory physiology, 7th edition. London: Churchill Livingstone Elsevier 2010;61-82

28. Jaswal DS, Leung JM, Sun J, Cui X, Li Y, Kern S, et al. Tidal volume and plateau pressure use for acute lung injury from 2000 to present: a systematic literature review. Crit Care Med 2014;42(10): 2278-2289.

29. Cooke CR, Watkins TR, Kahn JM, Treggiari MM, Caldwell E, Hudson LD, Rubenfeld GD. The effect of an intensive care unit staffing model on tidal volume in patients with acute lung injury. Crit Care 2008;12(6):R134

30. Bellani G, Laffey JG, Pham T, Fan E, Brochard L, Esteban A, et al. Epidemiology, patterns of care, and mortality for patients with acute respiratory distress syndrome in intensive care units in 50 countries. JAMA 2016;315(8):788-800.

This article is approved for Continuing Respiratory Care Education credit. For information and to obtain your CRCE

(free to AARC members) visit

www.rcjournal.com

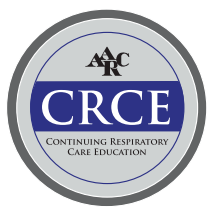

